\section{The Effect of 1-MCP on the Expression of Several Ripening-related Genes in Strawberries}

\author{
Andrea Balogh, Tímea Koncz, Viktória Tisza, Erzsébet Kiss, ${ }^{1}$ and \\ László Heszky \\ Department of Genetics and Plant Breeding, St. István University, H-2103 \\ Gödöllo, Hungary
}

Additional index words. cDNA-AFLP, cell wall, Fragaria $\times$ ananassa, gene expression

\begin{abstract}
To elucidate the role of ethylene in nonclimacteric fruit development and ripening, quantitative (cDNA-amplified fragment length polymorphism) cDNA-AFLP was used to visualize differential gene expression in four stages of ripening of strawberries (Fragaria ×ananassa Duch. 'Elsanta') treated with 1-methylcyclopropene (1-MCP), a competitive inhibitor of ethylene action. The proportion of clones affected by 1-MCP treatment was much higher in green than in white, pink, and red receptacle tissue. Three major cellwall-related genes were affected by 1-MCP and, thus, are putatively ethylene dependent: a ripening-repressed beta-galactosidase (Faßgal3), up-regulated by 1-MCP; a putative endo1,3-1,4-beta-D-glucanase (EGase), up-regulated in green and down-regulated in red fruit by 1-MCP; and a pectate lyase $\mathrm{B}$ (plB), expressed only in the red stage and significantly down-regulated by 1-MCP. Furthermore, we have identified genes encoding an alcohol dehydrogenase, a protein kinase-related protein, and a putative glutathione S-transferase, all ripening-induced and down-regulated by 1-MCP, suggesting that their regulation is at least partly ethylene dependent.
\end{abstract}

Strawberries (Fragaria $\times$ ananassa Duch.) are considered nonclimacteric, since they do not exhibit a peak in respiration and ethylene production during ripening. Ethylene is present in strawberries, but its influence on fruit ripening is not fully understood. Strawberries can ripen without exogenous ethylene treatment, but exogenous ethylene induces the acceleration of fruit color development and softening (Tian et al., 2000; Wills and Kim, 1995). The levels of ethylene in strawberries decrease from the green to white stage and then rise again slightly in the red-ripe stage (Perkins-Veazie et al., 1996). Ethylene may also play a role in ripening of other nonclimacteric fruit like orange and pineapple (Goldschmidt et al., 1993; Alonso et al., 1995; Cazzonelli et al., 1998). Ethylene induces enhanced anthocyanin accumulation in grapes (El-Kereamy et al., 2003), and a ripening-induced alcohol dehydrogenase gene shows ethylene regulation (Tesniere et al., 2004), suggesting that an ethylene signal transduction pathway could be involved in the control of nonclimacteric ripening.

1-Methylcyclopropene (1-MCP) inhibits ethylene action by binding to ethylene receptors so that ethylene cannot bind and elicit response,

Received for publication 17 June 2005. Accepted for publication $10 \mathrm{Aug}$. 2005. The research is supported by the Hungarian Scientific Research Fund (OTKA: TS 040887, T0 37861 and M 36630). We thank Dominque van der Straeten for making possible the cDNA-AFLP experiments at the Department of Molecular Biology (Ghent University, Belgium) and Giovanni Regilori (Rohm and Haas) for kindly providing free samples of 1-MCP.

${ }^{1}$ Author for correspondence; e-mail Kiss.Erzsebet@ mkk.szie.hu.

${ }^{2}$ HAS-SIU Research Group for Molecular Plant Breeding, Gödöllo. to allow global, quantitative gene expression analysis (Breyne et al., 2003).

\section{Materials and Methods}

'Elsanta' strawberries were harvested from a commercial farm near Ghent, Belgium. In total, 5 to 10 green, white, pink, and fully ripe red fruit (without removing the calyxes) were treated with $1-\mathrm{MCP}\left(15 \mathrm{~nL} \times \mathrm{L}^{-1}\right)$ in 5-L sealed jars for $10 \mathrm{~h}$ at $22^{\circ} \mathrm{C}$. 1-MCP was released from SmartFresh powder(Rohm and Haas, Philadelphia, Pa.). Control fruit were kept in the same conditions except for 1-MCP treatment.

cDNA-AFLP experiment. Total RNA was extracted from the fruit flesh according to Salzman et al. (1999). For RNA extractions minimum five fruit per ripening stage were used. First-strand cDNA synthesis was carried out starting from $10 \mu \mathrm{g}$ of total RNA, and quantitative cDNA-AFLP analysis was conducted as described by Breyne et al. (2003). Restriction enyzmes BstYI and MseI (New England Biolabs, Beverly, Mass.) were used, and for preamplifications an MseI primer without selective nucleotides was applied in pair with a BstYI primer containing a $\mathrm{C}$ as a selective nucleotide. (The primer sequences were 5'GACTGCGTAGTGATCC-3' for BstYI and 5'-GATGAGTCCTGAGTAA-3' for MseI). In the cDNA-AFLPreactions 48 primer combinations were tested, both primers contained two selective nucleotides. Amplification products were separated on $5 \%$ polyacrylamide gels using the SequiGen system (Bio-Rad, Hercules, Calif.). Dried gels were exposed to BioMax films (Kodak) and scanned with a PhosphorImager 445 SI (Amersham Biosciences, Little Chalfont, U.K.).

Characterization of AFLP fragments and quantitative measurement of the expression profiles. Based on the autoradiogram, the TDFs (transcript derived fragments) were excised from gels and hydrated in $100 \mu \mathrm{L}$ water for $1 \mathrm{~h}$ before PCR amplification of $2 \mu \mathrm{L}$ by using the same primers as in the selective amplification. Sequence information was obtained either by direct sequencing of the re-amplified product with the BstYI primer or after cloning the fragments in pGEM-T Easy (Promega, Madison, Calif.). The reactions were analyzed with an ABI Prism 310 Genetic Analyzer. Nucleotide and translated amino acid sequences were analyzed for homology to known gene sequences using the BLASTN and BLASTX programs. Quantitative measurement of the expression profiles was done as described by Breyne et al. (2003). Scanned gel images were quantitatively analyzed with the AFLP QuantarPro image analysis software (Keygene N. V., Wageningen, The Netherlands) by which all visible AFLP fragments were scored and individual band intensities were measured in each lane. The raw data were corrected for differences by using a total lane intensity correction. The intensity values were summed per lane for each primer combination and each of the sums was divided by the maximal summed value to yield the correction factors. Finally, all raw data were divided by these correction factors. For the corrected data, the coefficient of 
variation $(\mathrm{CV})(\mathrm{CV}=$ standard deviation/mean $)$ was calculated for each TDF, and a threshold of 2 was chosen for significantly differentially expressed genes.

\section{Results and Discussion}

From 86 green receptacle specific clones, 43 were down-regulated by 1-MCP, 33 were upregulated, and 10 clones showed no change in expression pattern after the treatment. Among the ripening induced clones a much lower percentage was regulated by $1-\mathrm{MCP}$. From 84 ripening specific TDFs, 20 were downregulated, 9 were up-regulated, the expression pattern of the rest was not effected by 1-MCP. The difference in response to 1-MCP of the green $(88 \%)$ and ripening fruit (34\%) might be due to their different sensitivity to ethylene, the consequence of the reduced endogenous ethylene production in the ripe fruit compared with the green receptacle. We focused on one ripening repressed and several ripening induced genes with modified expression pattern in response to $1-\mathrm{MCP}$ treatment. Fruit soften- ing, especially in strawberries, is an important postharvest quality trait, thus one of our main interest was to determine the effect of 1-MCP on genes related to cell-wall metabolism. We identified 3 cDNA-AFLP clones encoding enzymes responsible for cell wall loosening during cell expansion and fruit growth or ripening. One of them-C13M214M008-is ripening repressed, expressed only in the green receptacle, shows homology to betagalactosidase (Faßgal3) from strawberries (AJ278705), a cell wall hydrolase, mediating reversible wall loosening and thus allowing turgor-driven cell growth and expansion during fruit growth beside other cell wall modifying proteins. Trainotti et al. (2001) reported, that the transcript amount of this gene appears to be very high in flowers and in young fruits (both small and large green ones), then it gradually decreases during ripening and becomes almost undetectable in red fruits. In the experiment described by Trainotti et al. (2001), the exposure to ethylene of small green fruits and continuance of growth in the presence of ethylene did not seem to particularly affect the expression of Faßgal3. In contrary, in our case, Faßgal3 is significantly up regulated by 1-MCP (Fig. 1A).

The other clone (C23M21M011) accounts for a putative protein similar to endo-1,3-1,4beta-D-glucanase from rice (AAU10802). It is present in the green receptacle, where it is up regulated by $1-\mathrm{MCP}$, and in ripe fruit, down regulated by 1-MCP. Though the cDNA-AFLP fragment with homology to endo-1,3-1,4-betaD-glucanase shows no homology to any of the previously described EGase strawberry genes (Trainotti et al., 1999; Llop-Tous et al., 1999). To prove that we have identified a new member of the EGase gene family, the isolation of the full-length cDNA is in progress. The two, already described, EGase genes, FaEG1 and FaEG3, are predominantly expressed during the ripening process, in the case ofFaEG3, the gene expression was also observed in large green fruit and, at low levels, in young vegetative green tissues (Spolaore et al., 2003; Trainotti et al., 1999). There are no data about the ethylene regulation of these genes in strawberry. The sequence analysis of the FaEG1 and FaEG3
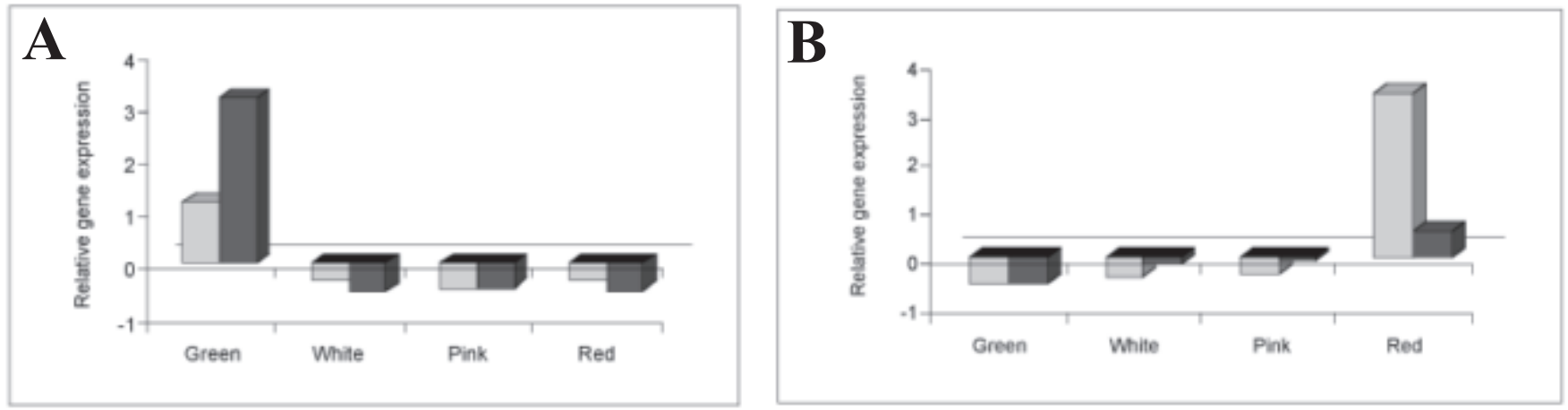

Fig. 1. Quantitative expression profile of genes encoding beta-galactosidase (A) and pectate lyase (B) in green, white, pink, and red fruit based on the relative, variance-normalized cDNA-AFLP expression data. Gray bar $=$ control fruit, black bar $=1$-MCP treated fruit.
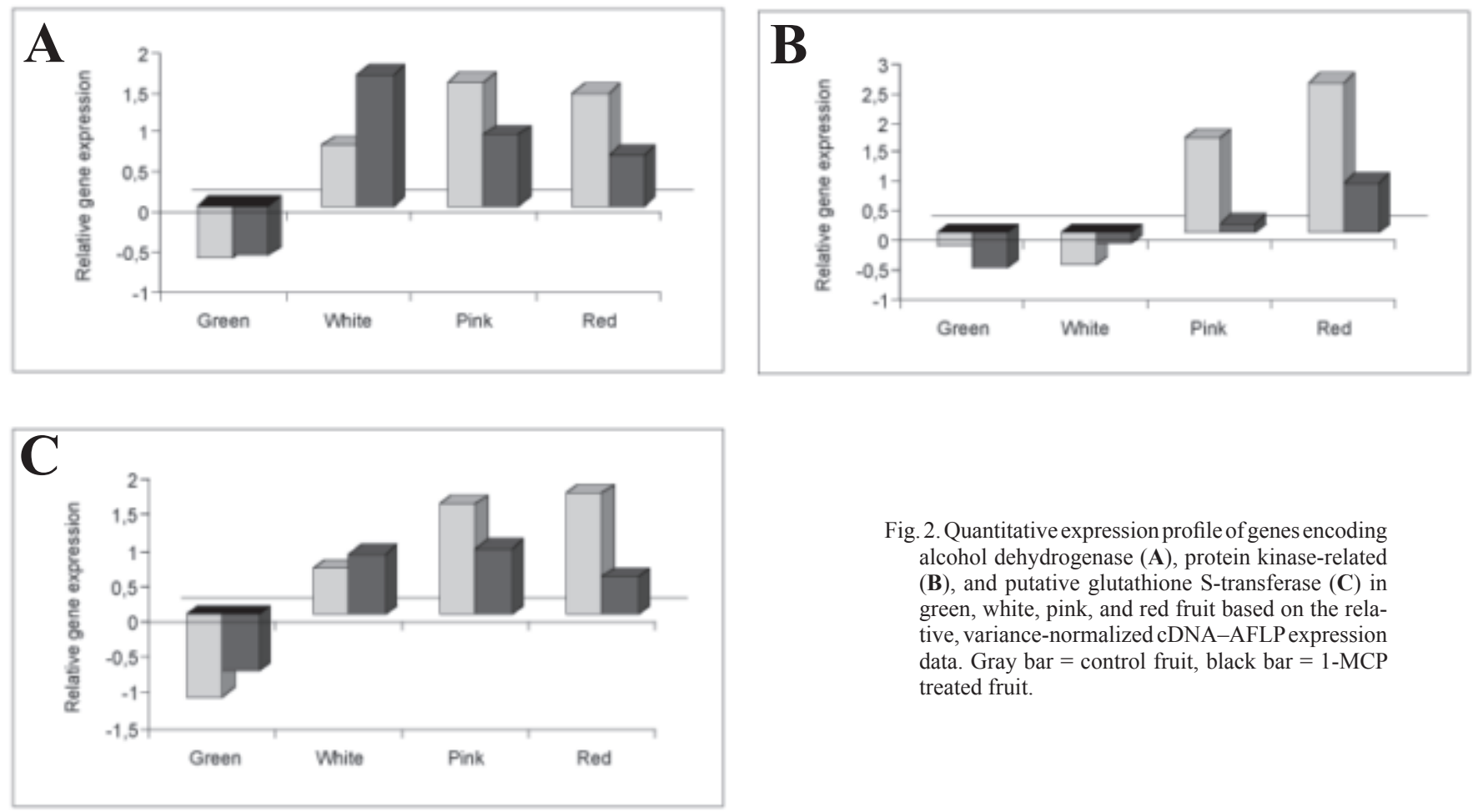

Fig. 2. Quantitative expression profile of genes encoding alcohol dehydrogenase $(\mathbf{A})$, protein kinase-related (B), and putative glutathione S-transferase (C) in green, white, pink, and red fruit based on the relative, variance-normalized cDNA-AFLP expression data. Gray bar $=$ control fruit, black bar $=1-\mathrm{MCP}$ treated fruit. 
promoters revealed the presence of ethylene responsive element, ATTTCAAA, identified in the promoter region of an ethylene responsive glutathione-S-transferase gene from Dianthus caryophyllus (Itzhaki et al., 1994) suggesting that these genes might be ethylene regulated. The fact that in our experiment 1-MCP affects the transcript level of endo-1,3-1,4-beta-Dglucanase sustains this possibility.

The third clone (C14M31M010) is ripening specific, encodes a pectate lyase B already identified in strawberry (AF339024) (BenitezBurraco et al., 2003). Pectate lyases randomly cleave $\beta-1,4$ linked galacturonosyl residues of pectines from the middle lamella and primary cell-walls of higher plants, resulting in the maceration of plant tissues (Collmer and Keen, 1986). It was already reported that the expression level of all members of the pectate-lyase gene family were strongly decreased when the red fruit were kept in controlled atmosphere enriched with $\mathrm{CO}_{2}$ (Benitez-Burraco et al., 2003). The same pattern was observed by us after 1MCP treatment, which dramatically decreases the gene expression level of pectate lyase B (Fig. 1B). Furthermore a ripening-related alcohol dehydrogenase homolog to tomato (S39508) was identified (C13M214M007). Transcript accumulation is induced during the onset of ripening, and 1-MCP partly inhibits the gene expression (Fig. 2A). Similar results were reported in a recent study, showing that the induction of VvADH2 transcription, both in grapevine berries at the inception of ripening and in cell suspensions, was reduced by 1-MCP. The same authors show that treating cell suspensions with 2-chloroethylphosphonic acid (2-CEPA), an ethylene-releasing compound, also resulted in a significant increase of ADH activity and VvADH2 transcription (Tesniere et al., 2004). These data suggest that ethylene could be involved in the control of $\mathrm{ADH}$ expression in nonclimacteric fruits. Another cDNA-AFLP fragment is similar to a gene encoding a putative glutathione Stransferase from tobacco (Q03666). It exposes a ripening induced pattern, while 1-MCP down regulates its transcript level in the pink and red stages (Fig. 2B). Strawberry glutathione S-transferases have already been identified as ripening regulated and oxidative stress induced (Aharoni et al., 2002) but there is no data about the involvement of ethylene in its regulation in this species. Ethylene regulation of several members of glutathione S-transferase gene family was reported in carnation (Itzhaki et al., 1994) and Arabidopsis (Zhong and Burns, 2003) during stress response or developmental processes (Mang et al., 2004). One of the most intriguing clones accounts for putative protein kinase from Arabidopsis (NP_177209). Its expression level increases during ripening, and is reduced by 1-MCP exposure in pink and red stages (Fig. 2C). Further functional analyses are needed to assess whether this gene could be involved in oxidative stress related signaling during ripening, and regulated by ethylene.

The genes, reported here, were submitted to NCBI data bank and appeared under the following accession numbers: DQ011162 (alcohol dehydrogenase), DQ022748 (putative endo-1,3-1,4-beta-D-glucanase), AAW82451 (putative glutathione-S-transferase), and AY679612 (putative protein kinase).

In this paper we described several genes identified by cDNA-AFLP, showing altered expression in response to 1-MCP, an ethylene inhibitor, thus gaining insight into some potentially ethylene dependent processes in strawberry ripening. However, the effect of $1-\mathrm{MCP}$ on prolongation of postharvest life of strawberries is contradictory (Bower et al., 2003), we found, that 1-MCP is suitable for scientific studies of nonclimacteric maturation at molecular level.

\section{Literature Cited}

Aharoni, A., L.C.P. Keizer, H.C. Van Den Broeck, R. Blanco-Portales, J. Munoz-Blanco, G. Bois, P. Smit, R.C.H. De Vos, and A.P. O'Connell. 2002. Novel insight into vascular, stress, and auxin-dependent and independent gene expression programs in strawberry, a nonclimacteric fruit. Plant Physiol. 129:1019-1031.

Alonso, J.M., J. Chamaro, and A. Granell. 1995. Evidence for the involvement of ethylene in the expression of specific RNAs during maturation of the orange, a nonclimacteric fruit. Plant Mol. Biol. 29:385-390.

Benítez-Burraco, A., R. Blanco-Portales, J. Redondo-Nevado, M.L. Bellido, E. Moyano, J.L. Caballero, and J. Munoz-Blanco. 2003. Cloning and characterization of two ripening-related strawberry (Fragaria $\times$ ananassa $\mathrm{cv}$. Chandler) pectate lyase genes. J. Expt. Bot. 54:633-645.

Blankenship, S.M. and J.M. Dole. 2003. 1-Methylcyclopropene: A review. Postharvest Biol. Technol. 28:1-25.

Bower, J.H., W.V. Biasi, and E.J. Mitcham. 2003. Effects of ethylene and 1-MCP on the quality and storage life of strawberries. Postharvest Biol. Technol. 28:417-423.

Breyne, P., R. Dreesen, B. Cannoot, D. Rombaut, K. Vandepoele, S. Rombauts, R. Vanderhaeghen, D. Inzé, and M.Zabeau. 2003. Quantitative cDNAAFLP analysis for genome-wide expression studies. Mol. Gen. Genomics 269:173-179.

Cazzonelli, C.I., A.S. Cavallaro, and R. Botella. 1998. Cloning and characterization of ripening-induced ethylene biosynthetic genes from nonclimacteric pineapple (Ananas comosus) fruits. Austral. J. Plant Physiol. 25:513-518.

Collmer, A. and N.T. Keen. 1986. The role of pectic enzymes in plant pathogenesis. Annu. Rev. Phytopathol. 24:383-409.

El-Kereamy, A., C. Chervin, J.P. Roustan,V. Cheynier, J.M. Souquet, M. Moutounet, J. Raynal, C. Ford, A. Latché, J.C. Pech, and M. Bouzayen. 2003. Exogenous ethylene stimulates the long-term expression of genes related to anthocyanin biosynthesis in grape berries. Physiol. Plantarum 119:175-182.

Goldschmidt, E.E., M. Huberman, and R. Goren. 1993. Probing the role of endogenous ethylene in the degreening of citrus fruits with ethylene antagonists. Plant Growth Regulat. 12:325-329.

Itzhaki, H., J.M. Maxson, and W.R. Woodson. 1994.
An ethylene-responsive enhancer element is involved in the senescence-related expression of the carnation glutathione-S-transferase (GST1) gene. PNAS USA 91:8925-8929.

Jersch, S., C. Scherer, G. Huth, and E. Schlösser. 1989. Proanthocyanidins as basis for quiescence of Botrytis cinerea in immature strawberry fruits. Zeitschrift für Pflanzenkrankheiten und Pflanzenschutz 96:365-378.

Jiang, Y., D.C. Joyce, and L.A. Terry. 2001. 1-Methylcyclopropene treatment affects strawberry fruit decay. Postharvest Biol. Technol. 23:227-232.

Ku, V.V.V., R.B.H. Wills, and S. Ben-Yehoshua. 1999. 1-Methylcyclopropene can differentially affect the postharvest life of strawberries exposed to ethylene. HortScience 34:119-120.

Llop-Tous, I., E. Dominguez-Puigjaner, X. Palomer, and M. Vendrell. 1999. Characterization of two divergent endo-beta-1,4-glucanase cDNAclones highly expressed in the nonclimacteric strawberry fruit. Plant Physiol. 119:1415-22.

Mang, H.G., E.O. Kang, J.H. Shim, S.Y. Kim, K.Y. Park, Y.S. Kim, Y.Y.Bahk, and W.T.Kim. 2004.A proteomic analysis identifies glutathione S-transferase isoforms whose abundance is differentially regulated by ethylene during the formation of early root epidermis in Arabidopsis seedlings. Biochim. Biophys. Acta. 167:231-239.

Perkins-Veazie, P.M., D.J. Huber, and J.K. Brecht. 1996. In vitro growth and ripening of strawberry fruit in the presence of ACC, STS or propylene. Ann. Appl. Biol. 128:105-116.

Salzman, R.A., T. Fujita, K. Zhu-Salzman, P.M. Hasegawa, and R.A. Bressan. 1999. An improved RNA isolation method for plant tissues containing high levels of phenolic compounds or carbohydrates. Plant Mol. Biol. Rpt. 17:11-17.

Sisler, E.C., E. Dupille, and M. Serek. 1996. Effect of 1-methylcyclopropene and methylenecyclopropene on ethylene binding and ethylene action on cut carnations. Plant Growth Regulat. 18:79-86.

Spolaore, S., L. Trainotti, A. Pavanello, and G. Casadoro. 2003. Isolation and promoter analysis of two genes encoding different endo-beta-1,4glucanases in the nonclimacteric strawberry. J. Expt. Bot. 54:271-277.

Tesniere, C., M. Pradal, A. El-Kereamy, L. Torregrosa, P. Chatelet, J.P. Roustan, and C. Chervin. 2004. Involvement of ethylene signalling in a nonclimacteric fruit: New elements regarding the regulation of $\mathrm{ADH}$ expression in grapevine. J. Expt. Bot. 55:2235-2240.

Tian, M.S., H.J. Prakash, H. Young, D.M. Burmeister, and G.S. Ross. 2000. Responses of strawberry fruit to 1-methylcyclopropene (1-MCP) and ethylene. Plant Growth Regulat. 32:83-90.

Trainotti, L., S. Spolaore, A. Pavanello, B. Baldan, and G. Casadoro. 1999. A novel E-type endo-beta-1,4-glucanase with a putative cellulose-binding domain is highly expressed in ripening strawberry fruits. Plant Mol. Biol. 40:323-332.

Trainotti, L., R. Spinello, A. Piovan, S. Spolaore, and G. Casadoro. 2001. B-Galactosidases with a lectin-like domain are expressed in strawberry. J. Expt. Bot. 52:1635-1645.

Wills, R.B.H. and G.H. Kim. 1995. Effect of ethylene on postharvest life of strawberries. Postharvest Biol. Technol. 6:249-255.

Zhong, G.V. and J.K. Burns. 2003. Profiling ethylene-regulated gene expression in Arabidopsis thaliana by microarray analysis. Plant Mol. Biol. 53:117-131. 